\title{
ONTOLOGIA E VIDA: SOBRE O TRABALHO EM HEGEL, MARX E LUKÁCS
}

Lucas Lipka Pedron ${ }^{1}$

\begin{abstract}
Resumo
Todo trabalho humano é um dispêndio de força de trabalho durante uma dada duração, que é capaz de gerar mais valor do que consome para se reproduzir. É da natureza do trabalho, enquanto dispêndio de força de trabalho, que produza mais do que o necessário para reproduzir, pelo metabolismo interno do corpo, a capacidade para despender a mesma força. E esse fato constitui a produtividade do trabalho humano. A racional exploração dessa produtividade inerente a atividade do trabalho é o que configura a mais-valia. É quanto o trabalho não se volta a uma atividade de mediação com a natureza, mas para a produção de mercadorias: a força de trabalho humana e social é usada para a produção de valores de troca. Enquanto forma particular, a mercadoria é uma anomalia social, e aqueles que ela influência, tem suas vidas condicionadas também por outros fatores histórico-sociais. Mas enquanto forma universal, a mercadoria, entendida como o processo de produção de objetos exclusivamente para troca, torna-se estrutural de todas as relações humanas. Ela passa a ser o modo de dominação efetiva sobre toda a sociedade, onde toda relação estabelecida entre os homens passa a ser feita por meio da mercadoria. Trata-se de destituir o homem da atividade com a qual ele produz sua humanidade; de reconectá-lo com essa atividade já como algo estranho e sem sentido para ele: o caráter desumanizado e desumanizante da relação mercantil é a reificação, a alienação do homem do mundo que constrói.
\end{abstract}

Palavras-chave: Lukács; reificação; trabalho; ontologia. 


\title{
ONTOLOGY AND LIFE: ABOUT LABOR IN HEGEL, MARX AND LUKÁCS
}

\begin{abstract}
All human labor is an expenditure of labor force on a given duration, which is capable of generating more value than it consumes to reproduce itself. Is in the nature of labor, as an expenditure of labor force, that it produces more than it is necessary to reproduce, by the intern metabolism of the body, the capacity to expend the same force. And this fact constitutes the productivity of human labor. The rational exploitation of this inherit productivity of the labor activity is what constitutes the surplus value. It's when labor isn't a mediation with nature anymore, but the merely the production of commodities: the human and social labor force is used to produce exchange value. As a particular form, commodity is a social anomaly, and those under it influence have their lives conditionated by other historical-social factors also. But as a universal form, commodity, understood as an exclusively process of production of objects for exchange, becomes structural of all human relations. It becomes the effective mode of domination over all society, where all relationship established among men is intermediated by the commodity. It's about destitute men of the activity with which they produce their humanity; of reconnecting them with this activity as something strange and meaningless to them: the inhumane and inhumanize character of mercantile relationship is the reification, the alienation of men of the world they themselves create.
\end{abstract}

Keywords: Lukács; reification; labor; ontology.

[...] quem de dentro de si não sai, vai morrer sem amar ninguém $[. . .]^{2}$

nem vem que não tem nenhum navio ou trem me leva a outrem ${ }^{3}$

\section{Os conteúdos da forma mercadoria}

A mercadoria se apresenta como uma forma específica pela qual duas coisas acontecem: por um lado, a mercadoria e suas formas (forma valor de uso e forma valor) são as formas como o trabalho aparece para o mundo. A saber, ora como trabalho concreto, materialmente

3 LEMINSKI, Paulo. nomes a menos. In: Toda poesia. São Paulo: Companhia das Letras, 2013. p. 318. 
determinado no objeto e no seu uso; ora como trabalho abstrato, materialmente indeterminado, expresso no valor de uso de uma mercadoria em comum que opera como a forma-dinheiro na equiparação de todas as mercadorias - e, a partir dessa mercadoria-dinheiro, como mera corporificação do tempo de trabalho que a produziu.

Por outro, a mercadoria se apresenta também, desenvolvidas e desdobradas suas formas de manifestação, não só como a forma específica sob a qual os objetos do trabalho se apresentam, mas também como a configuração social que articula, organiza e dispõe a atividade mesma do trabalho em vista de um fim. Ou melhor, ela organiza a atividade do trabalho na efetivação de um valor social que embasa sua existência como forma. Assim compreendida, ela não é meramente a determinação e delimitação dos objetos do trabalho no mundo, mas a forma social que organiza, a partir de si mesma e de seus fins, a atividade do trabalho.

E há uma diferença fundamental entre o trabalho que produz ocasionalmente mercadorias, e a organização do trabalho voltada exclusivamente para a produção de mercadorias; e essa diferença não é somente quantitativa, ela é principalmente qualitativa. A reificação, enquanto desefetivação do trabalhador, enquanto sua desumanização, só ocorre onde a forma de produção de mercadorias é a única forma de organização social do trabalho; e, consequentemente de toda a vida que se desenrola a partir de si. E esse desejo de universalidade, essa pretensão a fundamento único do tecido social é constituinte da própria forma mercadoria.

Mas como organizando o trabalho a mercadoria poderia organizar a sociedade? Como ela espelha a disposição do trabalho para sociedade enquanto totalidade? Enfim, como a mercadoria penetra em no conjunto das manifestações vitais da sociedade para remodelar esse conjunto segundo sua própria forma, sua própria imagem $?^{4}$ Isto ocorre em decorrência da natureza da atividade do trabalho: de seu caráter ontológico.

\section{Trabalho e obra}

O trabalho é ontológico. Ora pois, por que? Primeiro, por ontologia aqui entendemos a determinação daquilo que é; são os atributos fundamentais sem os quais uma coisa qual deixa de ser o que é, e com a qual passa a ser o que é. $O$ trabalho constitui parte integrante do ser humano; da sua mais universal determinação para a sua mais particular ocorrência. Isto porque o trabalho é, para os indivíduos mulheres, homens, etc., vida. Por um lado, é vida enquanto condições físicas de existência: é meio de subsistência, eterno metabolismo com a natureza para a manutenção da vida mesma. Por outro, é vida enquanto criação constante: criação, por um lado, de um mundo objetivo, tal como queria Hannah Arendt; por outro, criação enquanto engendramento singular de um gênero humano conforme a organização social do trabalho. 
Em A Condição Humana ${ }^{5}$, Hannah Arendt ${ }^{6}$ faz uma crítica a obra de Marx partindo de uma divisão categorial da atividade do trabalho em duas, essa mesma anunciada aqui. Divide o trabalho de Marx em duas categorias: trabalho (labor) e obra (work). A primeira é constituída de uma atividade cíclica de mediação entre o indivíduo e o ambiente que habita, eterno metabolismo com a natureza. A segunda é a atividade que deixa objetos no mundo, que constrói um mundo objetivo para gerações futuras.

Sua crítica a Marx se baseia em uma não separação, por parte de Marx, entre as duas categorias do trabalho. Tal confusão não o possibilitaria compreender a forma de dominação específica da era moderna e a alienação decorrente de tal dominação. Pois, quando separamos trabalho e obra, como categorias distintas, assumimos que: 1 - o metabolismo com a natureza, o trabalho, é nossa função animal, meramente repetitivo e mecânico, mas que nada cria, nada deixa no mundo, se não a energia que se desgasta. 2 - A criação de mundo objetivo, a obra, é a atividade que constrói um mundo composto de objetos que se defrontam a existência humana a protegendo e a possibilitando desenvolver; um mundo pronto e acabado, que acolhe os recém-chegados, e efetivam a existência, enquanto externalização do ser, daqueles que o criaram.

Sem adentramos muito na concepção arendtiana, o ponto principal de sua argumentação é que a era moderna destrói justamente essa diferença:

[...] O caso é inteiramente diferente na correspondente transformação moderna do processo da obra pela introdução do princípio da divisão do trabalho. Nesse caso, a natureza da obra é alterada e o processo de produção, embora não produza absolutamente objetos para o consumo, assume o caráter do trabalho. $[\ldots]^{7}$

Ou seja, o problema da assim chamada era moderna, é que ela transforma a atividade da obra em atividade de trabalho: mecânico, repetitivo, eterno. E o objeto da obra, que compunha o mundo em comum de objetos a serem usados, agora é um objeto como o objeto da atividade do trabalho: um objeto para ser consumido e extinguido. A era moderna organiza o trabalho para consumir o mundo em incessantes produtos, que não são mais usados, são destruídos com a mesma voracidade com que se destrói a natureza para produzi-los. técnica e apresentação de Adriano Correia. Rio de Janeiro: Forense Universitária, 2015. elogiar.". "Friends, Romans, countrymen, lend me your ears. I come to bury Ceasar, not to praise him." SHAKESPEARE, William. Julius Caesar. <http://shakespeare.mit.edu/julius_caesar/full. html>. Acesso em 21 de dezembro de 2018. (Ato 3, Cena 2, monólogo de Marco Antônio, versão nossa). Embora possa parecer arbitrário, elencamos Arendt como nossa interlocutora pois sua crítica nos ajudará a conceituar melhor a própria atividade do trabalho para Marx. 
Sem nos prolongarmos na crítica arendtiana a Marx, apontemos somente seu problema: ela é, sem mais nem menos, a própria crítica marxiana a sociedade capitalista. O que Arendt chama de era moderna é o que Marx chama de sistema capitalista. Ademais, a crítica arendtiana à era moderna não consegue dar conta da dimensão do problema da reificação da consciência, e da alienação do trabalho para a constituição do próprio mundo.

\section{Unidade orgânica}

O produto do trabalho é uma unidade. Ele reuniu em si todas as operações que o produziram. Todos os trabalhos que foram necessários para produzir um objeto de uso, se manifestam nele, seja pelo seu valor de uso ou por seu valor de troca. A unidade desse produto é orgânica. Isto é, a unidade que ele possui se manifesta a partir de perspectiva de união e integralização entre as partes que o compõem e que o ligam ao sujeito que o produziu. Sujeito e objeto seriam meros recortes; o trabalho os une na medida em que é despendido. Isto porque orgânico, para Lukács, como uma herança conceitual hegeliana, denota a forma como as coisas mantém uma unidade cuja toda parte que o compõe esteja integrada no todo do objeto.

A unidade orgânica de um objeto é dada pela totalização das partes que o compõem. Uma rosa, enquanto parte da roseira, tem um fim posto, uma função, integralizada dentro do organismo da roseira. A unidade de rosa e roseira é orgânica, pois as funções que a rosa desempenha, enquanto parte, se integram a totalidade da roseira, cumprindo não a finalidade da rosa, mas a finalidade da roseira. Orgânico denota justamente o ordenamento e a finalidade de uma parte quando ela está integrada à finalidade da totalidade a qual pertence.

Para isto atentemos a diferença posta por Hegel nos momentos do conceito ${ }^{8}$. São três os momentos do conceito: a universalidade, a particularidade, a singularidade. A universalidade ou o universal, é determinidade: um campo, um escopo de determinação daquilo que é. O universal é, assim, abstração em geral, mera essência sem existência 9 . A particularidade ou particular é o desenvolvimento do universal, é sua

Para a conceitualização do trabalho, como proposto nos Manuscritos Econômicos Filosóficos de Marx utilizamos algumas obras de Hegel. Principalmente as Enciclopédias das ciências filosóficas volumes 1 e 2 e a Fenomenologia do espírito. Para a diferença entre universal, particular e singular ver: HEGEL, Georg Wilhelm Friedrich. Enciclopédia das ciências filosóficas em compêndio: I-Ciência da Lógica. Tradução de Paulo Meneses e José Machado. v. 1. São Paulo: Loyola, 1995. p. 63-88; 291-297.

9 Efetividade, efetivar, efetivação compõem um conjunto de termos que associamos aqui ao campo conceitual marxiano e lukacsiano. Esse conjunto de termos, em nosso trabalho, designa o processo pelo qual o interior se conecta ao exterior: "A efetividade é a unidade, que veio-a-ser imediatamente, da essência e da existência, ou do interior e do exterior. A exterioridade do efetivo é o efetivo mesmo, de modo que nela fica igualmente o essencial, que só é essencial enquanto está em uma existência exterior imediata". HEGEL, 19995, p. 266. Assim, um trabalhador se efetiva na medida mesma que se exterioriza no mundo; na medida em que exterioriza a si mesmo pelo trabalho. 
reflexão na realidade. Como reflexão do universal, da determinidade, é sua determinação: particular é a negação do universal, porquanto faz dele uma existência, nega sua essência enquanto abstração geral.

No entanto, o particular é isolado, possui uma existência em si, e não se liga a indivíduos fora de si. A singularidade seria, então, o momento derradeiro do conceito, pois é o desenvolvimento do particular. O singular é o particular que estabelece conexões e vínculos entre si, portanto, que a partir de si se liga a outros, e compõem uma totalidade para além de sua individualidade. O singular é a negação do particular pois é a união do particular com o universal. Assim, o singular se faz concreto, porquanto estabelece relações entre os particulares, ao mesmo tempo que os vincula ao universal negado. E o momento do singular se faz também como a efetividade mesma do mundo, pois é a união da essência, o universal, com a existência, o particular.

Voltemos ao exemplo da rosa:

[...] O botão desaparece no desabrochar da flor, e poderia dizer-se que a flor o refuta; do mesmo modo que o fruto faz a flor parecer um falso ser-aí da planta, pondo-se como sua verdade em lugar da flor: essas formas não só se distinguem, mas também se repelem como incompatíveis entre si. Porém, ao mesmo tempo, sua natureza fluída faz delas momentos da unidade orgânica, na qual, longe de se contradizerem, todos são igualmente necessários. [...] $]^{10}$

Assim, cada momento particular da planta se nega, se refuta e se segue; sucedem-se um ao outro. Em nenhum deles a planta se revela em sua singularidade; pois ela só possui efetividade na sucessão e na união de todos os momentos "contraditórios". Todos compõem sua essência. Ademais, todos possuem uma função específica; sua finalidade se dá em vista do todo ao qual estão integrados: cada momento da planta existe com uma finalidade posta em vista da essência da planta. A efetividade da planta enquanto singular se dá justamente porque organiza e dispõem suas partes, seus momentos de existência, em vista de sua essência. E quando ela assim organiza suas partes, ela se constitui como um ser orgânico ${ }^{11}$, como uma unidade orgânica.

\section{Corpo inorgânico}

O indivíduo trabalhador, pela atividade do trabalho, destrói a unidade orgânica da natureza, para integrar a parte, a partir de si, em uma nova totalidade. A natureza, enquanto matéria-prima do trabalho,

10 HEGEL, Georg Wilhelm Friedrich. Fenomenologia do Espírito. Tradução de Paulo Meneses, com a colaboração de Karl-Heinz Efken e José Nogueira Machado. 9. ed. Petrópolis, RJ: Vozes; Bragança Paulista, SP: Editora Universitária São Francisco, 2014. p. 24. 
enquanto a materialidade a ser destruída e transformada pelo trabalho, se apresenta ao trabalhador como um corpo inorgânico:

A natureza é o corpo inorgânico do homem, a saber, a natureza enquanto ela mesma não é corpo humano. $\mathrm{O}$ homem vive da natureza significa: a natureza é o seu corpo, com o qual ele tem de ficar num processo contínuo para não morrer. Que a vida física e mental do homem está interconectada com a natureza não tem outro sentido senão que a natureza está interconectada com consigo mesma, pois o homem é uma parte da natureza. ${ }^{12}$

A natureza se coloca como o corpo inorgânico do trabalhador, que esse deve trabalhar para transformar em seu próprio corpo. Em outros termos: o trabalho é a vida imediata do indivíduo trabalhador. E “a vida imediata é [...] a vida em si alienada, e assim é a natureza inorgânica da vida subjetiva. Pois inorgânica é toda exterioridade [... $]^{\prime \prime} .{ }^{13}$ Isto é, o trabalho se realiza sobre uma unidade desconexa e não integralizada da natureza exterior a si. O trabalho transforma essa exterioridade para integralizá-la a si; o trabalhador se liga, pelo trabalho, naquilo sobre o que trabalha. Pela continua atividade do trabalho, o trabalhador, por um lado, se exterioriza, se coloca no mundo; por outro, faz da exterioridade seu meio de vida, retira do mundo a vida que ele mesmo produz no mundo.

Além disso, o indivíduo separa a natureza de si mesma fazendo com que a parte que ele retira da natureza se torne inorgânica com a totalidade a que antes pertencia; mas pelo trabalho ele transforma a parte que retirou da natureza em uma finalidade integrada em seu próprio corpo, tornando essa parte orgânica a ele trabalhador. Produto do trabalho e trabalhador se tornam uma unidade orgânica, através do trabalho. O mundo que se defronta ao indivíduo trabalhador, é um mundo que reflete a si sua própria interioridade que ele colocou no mundo; o mundo objetivo e o sujeito que se conectam, pela atividade do trabalho, em uma unidade orgânica. E isto na medida mesma em que o trabalho é esse reflexo de sua interioridade, de sua consciência; isto é, enquanto o trabalho se realiza segundo as finalidades daquele que trabalha.

[...] o trabalho, a atividade vital, a vida produtiva mesma aparece ao homem apenas como um meio para a satisfação de uma carência, a necessidade de manutenção da existência física. A vida produtiva é, porém, a vida genérica. É a vida engendradora de vida. No modo $(A r t)$ da atividade vital encontra-se o caráter inteiro de uma species, seu caráter genérico, e a atividade consciente livre é o caráter genérico do homem. A vida aparece mesma só como meio de vida. 
O animal é imediatamente um com a sua atividade vital. Não se distingue dela. É ela. O homem faz da sua atividade vital mesma um objeto da sua vontade e da sua consciência. [...] $]^{14}$

Temos agora uma outra composição. O trabalho, para além de realizar a vida individual do trabalhador, também engendra para os indivíduos mulheres, homens, etc. sua vida genérica. $O$ trabalho é a forma de individuação de cada trabalhador; é o momento onde nega a essência de sua humanidade (seu ser universal), enquanto determinidade abstrata, para se determinar, para determinar sua própria existência enquanto indivíduo (seu ser particular). Assim como todo animal, tem na sua vida imediata, na atividade vital do trabalho, sua existência determinada.

Mas o trabalho, para o humano, não é só sua vida imediata; ele não é somente em-si. Ao se desdobrar na realidade objetiva ele engendra um mundo objetivo que se lhe defronta como algo exterior a si, um reflexo de si mesmo; como se sua própria interioridade se apresentasse agora como exterior a si. O trabalho é a, primeiramente, a consciência em-si enquanto vida imediata do trabalhador; a partir do reflexo dos produtos do seu trabalho, sua consciência retorna a si como algo outro, como sua consciência para-si. ${ }^{15}$

$\mathrm{Ou}$, nas palavras de Marx:

[...] O engendrar prático de um mundo objetivo, a elaboração da natureza inorgânica é a prova do homem enquanto um ser genérico consciente, isto é, um ser que se relaciona com o gênero enquanto sua própria essência ou [se relaciona] consigo enquanto ser genérico. $[\ldots]^{16}$

Na união de sua vida imediata com sua vida reflexionada, o trabalhador efetiva sua relação com sua posição singular. Ele se efetiva enquanto humano na medida em se singulariza sua existência, a partir do trabalho, em consonância com sua própria essência.

\section{A forma mercadoria do trabalho}

Mas, o trabalho é uma atividade condicionada, delimitada por uma forma. Isto é, o trabalho é uma atividade que é realizada conforme formas constituídas histórica e socialmente. Nosso problema é a reificação. E ela se revela como problema justamente porque é o resultado de uma forma social que faz com que todo esse movimento do trabalho, todo o caráter ontológico do trabalho seja suprimido para a realização de uma vida sem vida. E o que caracteriza a forma mercantil, que engendra a reificação, é que o trabalho seja organizado em vista

\footnotetext{
14 MARX, 2004, p. 84.

15 Cf. HEGEL, 2014, p. 135-170.

16 MARX, 2004, p. 85.
} 
não de sua concretude e singularidade, mas de sua abstração: que o valor, o tempo de trabalho abstrato, seja o regulador e o organizador do trabalho na sociedade.

E essa abstração do trabalho só é possível pela própria qualidade com a qual podemos qualificá-lo. Para retirar de um objeto toda sua determinação qualitativa, todo trabalho qualitativo que se encerra nele, precisamos reduzir o trabalho (enquanto determinante dos valores da mercadoria) a sua forma mais simples; ou antes, a um dispêndio de força sem forma. Reduzido a sua mais simples manifestação, trabalho é substância formadora de valor ${ }^{17}$; isto é, o trabalho é a atividade que confere valor à mercadoria, tanto pela utilidade que lhe confere, como pela duração do trabalho que se cristaliza nela.

A força de trabalho que, ao ser despendida como massa de trabalho amorfa (sem forma), se cristaliza como valor na mercadoria. Como cristais do trabalho humano indiferenciado, se apresentam como uma objetividade fantasmagórica (gespenstige Gegenständlichkeit) ${ }^{18}$, uma alienação do trabalho enquanto externalização de si do trabalhador. A objetividade, a qualidade de se corporificar em um objeto, com a qual o trabalho se externaliza no produto do trabalho é a perda da objetividade do próprio trabalhador. É a perda da objetividade com a qual o trabalhador se efetiva no mundo.

Ao mesmo tempo em que o trabalhador, ao trabalhar, fixou seu trabalho no produto do trabalho, ele se desefetiva, por essa objetivação do trabalho na mercadoria, pois passa a se defrontar com o produto do seu trabalho como um ser estranho a si: "a objetivação como perda do objeto e servidão ao objeto" ${ }^{19}$. Mais do que isso, a alienação (entäusserung) do trabalho, enquanto a externalização do trabalho, a efetivação do trabalhador, se lhe defronta como uma atividade hostil e desumanizadora. Nos Manuscritos econômico-filosóficos, Marx atribui a isso uma natureza própria do trabalho enquanto externalização (entäusserung):

[...] o trabalho é externo (äusserlich) ao trabalhador, isto é, não pertence a seu ser, que ele não se afirma, portanto em seu trabalho, mas nega-se nele, que não se sente bem, mas infeliz, que não desenvolve nenhuma energia física e espiritual livre, mas mortifica sua physis e arruína o seu espírito. ${ }^{20}$

O primeiro item do capítulo 1 do Capital chama-se: "1. Os dois fatores da mercadoria: valor de uso e valor (substância do valor, grandeza do valor) ". Trabalho é substância formadora do valor, aquilo que confere valor à mercadoria. A substância desse valor é expressa no valor de uso da mercadoria: as propriedades físicas, químicas, geométricas etc. que são os resultados dos trabalhos qualitativamente determinados efetivados na mercadoria. A grandeza desse valor é expressa no valor de troca da mercadoria: o acúmulo de trabalho efetivados na mercadoria, independente da forma específica desses trabalhos. 
O trabalho é externo na medida mesma em que ele é alienado; isto é, na medida em que a força de trabalho que se gasta para realização de um trabalho é gasta não em vista de um fim definido para aquele que a gasta. $\mathrm{O}$ trabalho mortifica e desefetiva o trabalhador na medida em que é uma atividade realizada para outrem (portanto alienada), sem que ele domine as formas, os meios e o fim pelos quais a atividade se realiza. Essa desefetivação do trabalhador, essa externalização alienante, é a reificação decorrente do modo de produção capitalista, a essência da própria estrutura da mercadoria. Essa essência

[...] se baseia no fato de uma relação entre pessoas tomar o caráter de uma coisa e, dessa maneira, o de uma "objetividade fantasmagórica” que, em sua legalidade própria, rigorosa, aparentemente racional e inteiramente fechada, oculta todo traço de sua essência fundamental: a relação entre os homens. ${ }^{21}$

Aqui Lukács retoma a objetividade fantasmagórica decorrente da abstração do trabalho em Marx, a ligando diretamente ao caráter fetichista da mercadoria. Abstrair o trabalho, transformá-lo em tempo de dispêndio de força de trabalho sem forma ou determinação qualitativa, é o princípio operacional para a forma social de produção específica da forma mercadoria - a forma que separa e aliena o trabalhador do trabalho, enquanto sua atividade de efetivação, o seu colocar-se no mundo. A externalização do trabalhador se transforma em sua forma de estranhamento do mundo:

[...] a atividade pela qual o ser humano chega a tornar-se humano, o trabalho, pelo qual ele se diferencia do animal, evidencia-se justamente como o meio para constantemente voltar a anular essa diferença. $\mathrm{O}$ ser humano se relaciona com a sua mais essencial manifestação de vida como se fosse algo exterior a ele; o próprio trabalho, a sua essência propriamente dita, não é, para ele, a satisfação de uma necessidade, mas apenas um meio para satisfazer necessidades distintas desse trabalho. O caráter exterior e estranho do trabalho "evidencia-se de forma pura no fato" de que se foge do trabalho como da peste no momento em que não existe coerção física. $[. . .]^{22}$

Sob a forma mercadoria, o trabalho deixa de ser a efetividade do trabalhador; ele passa a ser justamente seu estranhamento. Porque ele perdeu o domínio sobre a atividade, isto é, porque o trabalho que ele realiza se realiza em vista de fins que ele desconhece, que lhe são alheios, seu trabalho se torna a forma como ele vai ao mundo, sem voltar a si. É no domínio da atividade, desde seu início, enquanto imagem que orienta e conduz o processo, até no fim, seja como o fim da atividade, 
como a realização de uma vontade e um objetivo pelo processo, que o trabalho é efetivo. Quando ele se realiza para fins externos, a atividade do trabalho torna-se, como para o animal, meramente imediata; meramente vida, meramente satisfação de necessidades - por mais que distintas da atividade mesma. ${ }^{23}$

A objetividade fantasmagórica é produto dessa forma social de produção; é através da abstração do trabalho que as relações entre homens expressas nos produtos do trabalho tomam o caráter de uma relação entre coisas. No entanto, a própria relação entre os homens só pode existir por conta dessa abstração do trabalho; e o que denota a reificação não é propriamente essa abstração, mas a universalização dessa abstração.

Como aponta Marx

O segredo da expressão do valor, a igualdade e equivalência de todos os trabalhos porquê e na medida em que são trabalho humano em geral, só pode ser decifrado quando o conceito de igualdade humana já possui a fixidez de um preconceito popular. Mas isso só é possível em uma sociedade em que a forma-mercadoria é a forma universal do produto do trabalho [...]. ${ }^{24}$

A universalidade com a qual a forma-mercadoria se impõe na sociedade, aponta justamente sua mais verídica propriedade, "Pois é somente como categoria universal de todo ser social que a mercadoria pode ser compreendida em sua essência autêntica" 25 . Essa universalidade, que determina e delimita toda manifestação ontológica, ou do ser social, a partir da forma mercadoria é expressa na tipologia das falsas consciências; ou, em termos mais prontamente marxianos, na consciência de classe.

\section{A consciência classe - ou a posição ontológica engendrada pela forma social do trabalho}

Atribui-se a consciência de classe alguma espécie de estado de consciência psicológica que se obtém do mundo. Certamente uma interpretação advinda de leituras permeadas pela psicanálise. Aqui precisamos corrigir tal equívoco se quisermos entender a relação dos indivíduos com a História. Consciência de classe não é algo que se alcança; muito menos é algo que descreve um certo estado mental com relação a realidade do mundo. A consciência de classe é, segundo Lukács: tivação da criança no seio da família. Cf. BENJAMIN, Walter. Reflexões sobre a criança, o brinquedo e a educação. Tradução de Marcus Vinicius Mazzari. São Paulo: Editora 34, 2009. Cf. GONZALES, Amanda. Transformações de Emília nas obras de Monteiro Lobato: a boneca que virou gente. Trabalho de conclusão de curso (Licenciatura em Letras - Português) - Setor de Ciências Humanas, Universidade Federal do Paraná. Curitiba, 2018. p. 8-10. 
[...] uma inconsciência, determinada conforme a classe, de sua própria situação econômica, histórica e social. Essa situação é dada como uma relação estrutural determinada, como um nexo formal definido, que parece dominar todos os objetos da vida. Consequentemente, a "falsidade" e a "ilusão" contidas em tal situação real não são arbitrárias, mas, ao contrário, a expressão mental da estrutura econômica e objetiva. ${ }^{26}$

A consciência de classe é a consciência adjudicada a indivíduos de uma classe conforme as determinações materiais, históricas e sociais de sua vida. ${ }^{27}$ Não dizem respeito a propriamente o que eles pensam ou deveriam pensar; ou como agem ou deveriam agir. Mas antes de conhecer o que tais indivíduos teriam pensado, sentido, desejado, mesmo agido, se conseguissem apreender a realidade como totalidade. Isto porque toda consciência que os indivíduos podem ter da realidade é justamente uma "falsa consciência" do mundo; e é falsa consciência pois não consegue apreender a sociedade que se apresenta em sua totalidade.

A totalidade é a realidade do mundo; e a falsa consciência não é propriamente uma consciência alienada do mundo, da realidade. A falsa consciência é justamente a consciência adjudicada a indivíduos de uma classe conforme as determinações materiais de sua vida. A consciência de classe é um espectro de falsas consciências, determinadas conforme a classe, que determinam como o que de fato os indivíduos podem ou poderiam pensar a partir da posição que ocupam.

Antes de nos debruçarmos sobre a determinação duplamente dialética da falsa consciência, cabe ainda elucidar um outro corriqueiro equívoco. É comum compreender o conceito de classe como um recorte econômico ou social. Associa-se ao conceito de classe uma dada classificação correspondente a uma categoria econômica. E reduz-se essa categoria classificatória econômica a uma faixa de renda familiar e acumulo de bens: a uma categoria classificatória de acúmulo de propriedade privada (pois o salário nada mais é do que propriedade privada) ${ }^{28}$ - mesmo que tais propriedades privadas não sejam necessariamente transformadas em capital.

Marx define a classe, já em 1848, no Manifesto do Partido Comunista, da seguinte maneira: "Nas mais remotas épocas da História, verificamos, quase por toda parte, uma completa estruturação da sociedade em classes distintas, uma múltipla gradação das posições sociais." 29 É justamente o entendimento da classe como uma posição social que

\footnotetext{
26 Ibidem, p. 143.

27 Cf. MÉSZÁROS, István. Para além do capital: Rumo a uma teoria da transição. Tradução de Paulo César Castanheira e Sérgio Lessa. São Paulo: Boitempo; Campinas, SP: Editora da Unicamp, 2002. p. 399-404.

28 Cf. MARX, 2004, p.88.

29 MARX, Karl; ENGELS, Friedrich. Manifesto do Partido Comunista. Tradução de Álvaro Pina e Ivana Jinkings. 1. Ed. rev. São Paulo: Boitempo, 2016. p. 40. Grifo nosso.
} 
nos interessa. ${ }^{30}$ Como posição social, a classe não é um recorte de renda de um indivíduo, ou de um grupo de indivíduos; como posição social a classe é o encontro de diversas determinações materiais, históricas e sociais (e, justamente por isso, econômicas) cuja vida de um indivíduo é permeada.

Mas o que precisamente determinam essas determinações? O que é, de fato, essa posição social ocupada pela classe? Onde se situa essa tal posição? Lukács aborda esse problema propondo a seguinte solução (na esteira do que chama de "movimento posterior" as obras de Marx e Engels):

De uma maneira funesta, tanto para a teoria como para o proletariado, a principal obra de Marx interrompe-se justamente no momento em que aborda a definição de classe. [...] No espírito do marxismo, a divisão da sociedade em classes deve ser determinada segundo a posição no processo de produção. ${ }^{31}$

Assim, decisivo para a classe e para a própria consciência é o trabalho. É o trabalho que determina a classe. Ou melhor, é a posição que se ocupa na disposição e organização social do trabalho que determina um indivíduo segundo uma classe; pois a organização social do trabalho é a organização do processo de produção. A classe é a posição que se ocupa nessa organização social do trabalho.

Com essa definição do conceito de classe, podemos compreender como é possível transpor as diversas lutas sociais para dentro da esquemática geral, sem reduzir as particularidades ou diminuir a própria luta, da luta de classes. Aqui nos fiamos em Silvia Federici:

Se é verdade que na sociedade capitalista a identidade sexual se transformou em suporte específico para as funções do trabalho, o gênero não deveria ser tratado como uma realidade puramente cultural, mas como uma especificação das relações de classe. [...] Para reformular o que apresentei: se na sociedade capitalista a 'feminilidade' foi construída como uma função-trabalho que oculta a produção da força de trabalho sob o disfarce de um destino biológico, a história das mulheres é a história das classes, e a pergunta que devemos nos fazer é se foi transcendida a divisão sexual do trabalho que produziu esse conceito em particular. ${ }^{32}$

Para além da compreensão da mulher como uma classe específica, como uma posição específica da vida na sociedade, aqui capitalista, podemos estender a luta de classes também para a luta de povos: isto

30 Cf. MAESO, Benito Eduardo. As diferenças em comum: Deleuze, Marx e o agora. Tese (doutorado em Filosofia) - Setor de Ciências Humanas, Universidade Federal do Paraná. Curitiba, 2018. p. 331-332.

31 LUKÁCS, 2012, p. 133.

32 FEDERICI, Silvia. Calibã e a bruxa: Mulheres, corpo e acumulação primitiva. Tradução: coletivo Sycorax. São Paulo: Elefante, 2017. p. 31. 
é, pela luta por modos outros de organização da vida. Marx descreve, no capítulo 24 do Capital $^{33}$, o processo de acumulação primitiva: é o processo de despossessão da terra, da desvinculação das e dos trabalhadores com aquilo que lhes serve de meio de vida, como meio de trabalho. Federici traça paralelos dessa relação de despossessão dos indivíduos trabalhadores da terra, com o processo de acumulação primitiva sobre o corpo da mulher: a despossessão do corpo, voltando o corpo da fêmea para a reprodução da força de trabalho, não mais de trabalho. Viveiros de Castro, na famosa aula pública Os Involuntários da Pátria (durante o ato Abril Indígena na Cinelândia no Rio de Janeiro, em 20 de abril de 2016), traça os mesmos paralelos com outras formas de despossessão:

A terra é o corpo dos índios, os índios são parte do corpo da Terra. A relação entre terra e corpo é crucial. A separação entre a comunidade e a terra tem como sua face paralela, sua sombra, a separação entre as pessoas e seus corpos, outra operação indispensável executada pelo Estado para criar populações administradas. Pense-se nos LGBT, separados de sua sexualidade; nos negros, separados da cor de sua pele e de seu passado de escravidão, isto é, de despossessão corporal radical; pense-se nas mulheres, separadas de sua autonomia reprodutiva. Pense-se, por fim mas não por menos repugnante, no sinistro elogio público da tortura feito pelo canalha Jair Bolsonaro - a tortura, modo último e mais absoluto de separar uma pessoa de seu corpo. Tortura que continua - que sempre foi - o método favorito de separação dos pobres de seus corpos, nas delegacias e presídios deste país tão "cordial" [...]. ${ }^{34}$

Assim, retomando, a classe é um lugar que se ocupa marcado pela violência sofrida para que se conforme a tal ocupação. Mas também é marcada pelo processo de (r)existência com relação a nova posição a que é conformado, e de resgate da posição que ocupava ou busca ocupar em um modo outro de organização da vida. A consciência é a perspectiva que surge dessa luta e desse lugar que se ocupa. Ou, como definimos acima, uma perspectiva que pode surgir a partir dessa posição. Essa perspectiva que surge do mundo, a consciência de classe, que é determinada, tanto como posição social ou como posição no processo de produção, a partir da organização social do trabalho - portanto, da produção e reprodução da vida mesma -, essa perspectiva surge como uma relação com a sociedade como totalidade. Mas, e aqui entra o jogo duplamente dialético da consciência, essa relação com a totalidade sempre é uma perspectiva. Assim:

34 VIVEIROS DE CASTRO, Eduardo. Os Involuntários da Pátria. Rio de Janeiro: N-1, 2016. pp. $17-18$. 
[...] é somente nessa relação que se revela a consciência que os homens têm de sua existência, em todas as suas determinações essenciais. De um lado, aparece com algo subjetivamente justificado na situação social e histórica, como algo que pode e deve ser compreendido enquanto "correto". Ao mesmo tempo, aparece como algo que, objetivamente, é passageiro em relação a essência do desenvolvimento social, não se conhece e não se exprime adequadamente, portanto, como "falsa consciência". Por outro lado, na mesma relação, essa consciência revela não ter conseguido alcançar subjetivamente os fins que atribuiu a si mesma, enquanto promoveu e atingiu os fins objetivos do desenvolvimento social, que ela não conhecia e não desejou. ${ }^{35}$

Sob a forma subjetiva, engendrada a partir da forma social-histórica, os indivíduos têm uma compreensão da realidade pautada na perspectiva da posição que ocupam: sua classe. Portanto, a partir da sua posição, tem uma apreensão da sociedade, isto é, da sociedade enquanto totalidade, portanto, da realidade, "correta". Correta pois é uma consciência adjudicada a partir das determinações materiais de sua vida. Ao mesmo tempo, por ser uma perspectiva limita pela posição que ocupa, todo fim que busca nunca se concretizam; justamente porque não apreende a totalidade de fato, mas a perspectiva da totalidade a partir de sua posição.

Sob a forma objetiva, é uma consciência que se exprime adequadamente, que não apreende de fato o processo social em seu desenvolvimento. Justamente porque subjetivamente não apreende a totalidade, mas uma perspectiva. Assim, a consciência que surge dos indivíduos, a partir da posição que ocupam no mundo, é uma falsa consciência; uma consciência incompleta e afastada do devir do mundo. Mas justamente porque se manifesta, objetivamente, como uma falsa consciência, como uma não compreensão da totalidade, pode desenvolver a forma histórica a qual pertence, os fins objetivos do desenvolvimento social. Aqueles fins e relações que a consciência desconhece, mas que realiza.

Aqui poderia se objetar: tal definição da consciência de classe como uma inconsciência, com uma falsa consciência atribuída conforme a posição no processo de produção, e a independência das forças motrizes da história (portanto, da própria História) da consciência que os indivíduos têm delas, também parece excluir da História qualquer mudança operada a partir de uma atividade humana. A isto objetaríamos que, conforme a relação duplamente dialética da falsa consciência, não ter consciência dos fins que se realiza não significa não realizar nenhum fim. Isto é evidente pela separação das formas subjetivas e objetivas com as quais as ações humanas se desenrolam no mundo. Nas palavras de Lukács:

Parece que [...] todo papel decisivo no processo histórico estaria sendo subtraído da consciência. Certamente, os reflexos 
conscientes das diversas etapas do desenvolvimento econômico permanecem fatos históricos de grande importância; certamente, o materialismo dialético, assim constituído, não contesta de modo algum que os homens cumprem e executam conscientemente seus atos históricos. Mas [...] trata-se de uma falsa consciência. ${ }^{36}$

Portanto, subjetivamente desconhecemos a totalidade; mas objetivamente desenvolvemos seus fins. Pois é justamente a falsa consciência, como uma consciência corretamente atribuída conforme a posição que se ocupa na organização social da vida, que possibilita que desconheçamos os fins específicos que realizamos: que a práxis, com força motriz da história, seja independente da consciência que temos dela, enquanto a realizamos.

\section{Referências}

ARENDT, Hannah. A Condição Humana. 12. ed rev. Tradução de Roberto Raposo. Revisão técnica e apresentação de Adriano Correia. Rio de Janeiro: Forense Universitária, 2015.

BENJAMIN, Walter. Reflexões sobre a criança, o brinquedo e a educação. Tradução de Marcus Vinicius Mazzari. São Paulo: Editora 34, 2009.

FEDERICI, S. Calibã e a bruxa: mulheres, corpo e acumulação primitiva. Tradução de coletivo Sycorax. São Paulo: Elefante, 2017.

GONZALES, Amanda. Transformações de Emília nas obras de Monteiro Lobato: a boneca que virou gente. Trabalho de conclusão de curso (Licenciatura em Letras - Português) - Setor de Ciências Humanas, Universidade Federal do Paraná. Curitiba, 2018.

HEGEL, Georg Wilhelm Friedrich. Enciclopédia das ciências filosóficas em compêndio: I - Ciência da Lógica. Tradução de Paulo Meneses e José Machado. v. 1. São Paulo: Loyola, 1995.

HEGEL, Georg Wilhelm Friedrich. Enciclopédia das ciências filosóficas em compêndio: II - A Filosofia da Natureza. Tradução de José Machado e Paulo Meneses. v. 2. São Paulo: Loyola, 1997.

HEGEL, Georg Wilhelm Friedrich. Fenomenologia do Espírito. Tradução de Paulo Meneses, com a colaboração de Karl-Heinz Efken e José Nogueira Machado. 9. ed. Petrópolis, RJ: Vozes; Bragança Paulista, SP: Editora Universitária São Francisco, 2014. 
LUKÁCS, György. História e Consciência de Classe: estudos sobre a dialética marxista. Tradução de Rodnei Nascimento. $2^{a}$. ed. São Paulo: Martins Fontes, 2012.

MAESO, Benito Eduardo. As diferenças em comum: Deleuze, Marx e o agora. Tese (doutorado em Filosofia) - Setor de Ciências Humanas, Universidade Federal do Paraná. Curitiba, 2018.

MARX, Karl. Manuscritos Econômico-Filosóficos. Tradução de Jesus Ranieri. São Paulo: Boitempo, 2004.

MARX, Karl. O Capital: Crítica da economia política. Tradução de Rubens Enderle; Celso Naoto e Márcio Bilharinho Naves. São Paulo: Boitempo, v. I, 2013.

MARX, Karl; ENGELS, Friedrich. Manifesto do Partido Comunista. Tradução de Álvaro Pina e Ivana Jinkings. 1. Ed. rev. São Paulo: Boitempo, 2016.

MÉSZÁROS, István. Para além do capital: Rumo a uma teoria da transição. Tradução de Paulo César Castanheira e Sérgio Lessa. São Paulo: Boitempo; Campinas, SP: Editora da Unicamp, 2002.

REICHELT, Helmut. Sobre a estrutura lógica do conceito de capital em Karl Marx. Tradução de Nélio Schneider. Campinas, SP: Editora da Unicamp, 2013. 